\title{
Current practices of clinical waste management in private clinics, Selangor, Malaysia
}

\begin{abstract}
Clinical waste comes from different sources, including hospitals, clinics, medical and dental surgeries, etc. Clinical waste is potentially dangerous therefore it is important to practice special caution in the handling and management of clinical waste in order to minimize its potential danger to public health or pollution to the environment. Management of clinical waste continues to be a major challenge in most healthcare facilities of the developing world. The definition of clinical waste has historically been used to describe waste produced from healthcare and similar activities that pose a risk of infection or that may prove hazardous. Lack of appropriate legislation, lack of specialized clinical staff and lack of awareness and effective control are the main reasons of the mismanagement of clinical waste in most of the cases. The aim of this study is to determine the clinical waste composition and its management system in private clinics of Selangor, Malaysia. A number of private clinics in Selangor was selected using simple random sampling method for this study. An appropriately designed questionnaire and semi-structured interview used for the purpose of data collection. The quantity of $\mathrm{CW}$ generated from most of the private clinic is less than $1 \mathrm{~kg} / \mathrm{day}$ which would increase the possibility of disposing $\mathrm{CW}$ as general waste and at the same time the monitoring of CWM in private clinic is insufficient. The results of this study give a comprehensive understanding of current clinical waste composition and its management system in Selangor and therefore there are rooms for improvement.
\end{abstract}

Keyword: Clinical waste; Management; Private clinics; Selangor 